\title{
Primary Antiphospholipid Syndrome (APS) and Systemic Lupus Erythematosus (SLE) with Multiple Deep Vein Thrombosis- Case Report
}

Dr. Krishna Kumar Dhakchinamoorthi ${ }^{1^{*}}$, Dr. Ann Mary Alex ${ }^{2}$, Dr. Nikhil Cherian Sam ${ }^{2}$, Dr. Jeevanantham $\mathrm{R}^{2}$, Mohamed Sulaiman $\mathrm{G}^{3}$, Irene Mariya Kishore ${ }^{3}$, Dr. Ashwin Karuppan $\mathrm{V}^{4}$

${ }^{1}$ Professor and Head, Department of Pharmacy Practice/PharmD, C.L. Baid Metha College of Pharmacy, Tamil Nadu, India

${ }^{2}$ PharmD Internship Trainee, ${ }^{3}$ PharmD student, C.L. Baid Metha College of Pharmacy, Tamil Nadu, India

${ }^{4}$ Consultant, Department of General Medicine, Gleneagles Global Hospital \& Research, Global Health City, Chennai, India

DOI: $10.36347 /$ sjmcr.2020.v08i10.004

| Received: 22.09.2020 | Accepted: 03.10.2020 | Published: 10.10.2020

*Corresponding author: Dr. Krishna Kumar Dhakchinamoorthi, M. Pharm., PhD

Abstract

Case Report

Antiphospholipid syndrome (APS) is a complex disorder and associated with thrombosis which causes significant morbidity with antiphospholipid antibodies (aPL). Many percentages of patients with the systemic lupus erythematosus (SLE) were tested positive for aPL antibodies. However, patients in the early stage do not report to have SLE symptoms. In the present case, the primary APS antiphospholipid antibodies were present with multiple deep vein thrombosis. A 24-year-old female patient was admitted to the hospital for the complaints of excruciating pain over the left lower limb and swelling that extended till the groin. Further, the investigations were confirmed antiphospholipid syndrome through positive results of tests for anti-cardiolipin (ACLA), anti-nuclear antibody (ANA) and beta-2 glycoprotein. However, the presence of SLE is confirmed only by direct coombs test. In this case, SLE with APS antibody not triggered the syndrome, and there were no signs of any SLE syndrome, however, patients had multiple deep vein thrombosis and underwent for the catheter-directed thrombolytic procedure. In the present case, early diagnosis and sufficient treatment are required to prevent the progression of the disease.

Keywords: Antiphospholipid Lupus Vein Thrombosis Erythematosus.

Copyright (C) 2020 The Author(s): This is an open-access article distributed under the terms of the Creative Commons Attribution 4.0 International License (CC BY-NC 4.0) which permits unrestricted use, distribution, and reproduction in any medium for non-commercial use provided the original author and source are credited.

\section{INTRODUCTION}

Antiphospholipid syndrome (APS) is an autoimmune disorder characterized by the presence of antiphospholipid antibodies (aPL)[1]. Venous thromboembolism (VTE) is a more common condition in APLS due to the stimulation of thrombosis induced by APS antibodies interfering in the blood-clotting pathway [2]. APS is also associated with several other complications in pregnant women such as miscarriage, severe preeclampsia, preterm delivery and infertility [3]. Other APS related major cardiovascular complications are mitral and aortic valve lesions, seizure disorder, accelerated cognitive decline, and nephropathy [4]. Also causes hemolytic anemia and thrombocytopenia. APS is diagnosed and classified into two major categories either primary or secondary syndrome. The primary syndrome occurs as a result of positive APL antibodies with thrombosis but not presented with any other related complications [5]. The secondary syndrome occurs with thrombosis and presents with other autoimmune complications of systemic lupus erythematosus (SLE)[6]. The severe form of this syndrome causes multiple major organ failures due to multiple thromboses, this condition is termed "catastrophic antiphospholipid syndrome" (CAPS) also referred as Asherson syndrome, leads to collapse and death [7]. Patient's positive for aPLs can develop irreversible organ damage. It was reported that within five years of diagnosis, more than half of SLE patients can develop organ damage. Further, primary APS patients can develop organ damage with later than ten years of disease $[8,9]$.

\section{CASE RePORT}

A 24-year-old female patient was admitted to the hospital for the complaints of excruciating pain over the left lower limb and swelling that extended till the groin. The complaints were gradual and it was presented over a month. No history of trauma or surgery. Her general and systemic examinations were within the normal range, except on examination of the leg revealed that the signs of hot flushing, swelling, and tenderness. Further following investigations were done to reveal the disorder. 


\section{Hematological investigations}

The baseline hematological investigation was within the normal range. The hematocrit values were: hemoglobin $10.4 \mathrm{~g} / \mathrm{dL}$, packed cell volume $34 \%$, WBC count 9110 cells $/ \mathrm{mm}^{3}$, RBC count $3.8 \mathrm{mill} / \mathrm{mm}^{3}$, platelet count $3.58 \mathrm{~L} / \mathrm{mm}^{3}$, neutrophils $66.3 \%$, lymphocytes $24.8 \%$, monocytes $5.2 \%$, eosinophils $3.2 \%$, basophils $0.5 \%$, mean cell volume $89 \mu \mathrm{m}^{3}$, mean corpuscular volume $27 \mathrm{pg} / \mathrm{cell}$, erythrocyte sedimentation rate $10 \mathrm{~mm} / \mathrm{L}$ and coagulation profile prothrombin time $12.2 \mathrm{secs}$, INR 1.02 were within the normal range. Random blood sugar $108 \mathrm{mg} / \mathrm{dl}$, sodium $138 \mathrm{mmol} / 1$ and potassium $4.2 \mathrm{mmol} / \mathrm{L}$.

\section{Doppler Venogram Ultrasound}

Diffused soft tissue echogenic thrombosis noted in the left internal iliac vein extending proximally into the common iliac vein and distally into the femoral vein and popliteal vein. Diffuse edema of the left lower limb (Figure 1).

\section{CT Lower Limb Venogram}

Acute thrombus on the left external iliac vein, common femoral vein, superficial femoral vein, popliteal vein, anterior tibial vein, and posterior tibial vein (Figure 2).

Further, the investigations were performed to confirm antiphospholipid syndrome, tests for anticardiolipin IgM (ACLA), anti-nuclear antibody (ANA), beta-2 glycoprotein IgG and beta-2 glycoprotein IgM were positive and revealed the diagnosis for APS syndrome. Later the patient was advised to take the coombs test, the test result shows that the patient was present with positive for the direct coombs test and negative for the indirect Coombs test. Based on the differential diagnosis the patient was diagnosed with the primary antiphospholipid syndrome with deep vein thrombosis.

Due to the thrombus location and prognosis the patient underwent minor catheter-directed thrombolysis (CDT) to the post-thrombotic syndrome of the leg. For pre-procedure the patient was administered with enoxaparin-60 mg/0.6 ml, followed by continuous infusions of Heparin (1000U and 5000U). The aPTT levels were continuously monitored every 12 hours from day one to day three before the procedure (ranges from 118.4 on initial, 60.1, 41.6, and 37.4 before surgery).

During the catheter-directed thrombolytic procedure, she was managed with IVC filter placement. The post-procedure patient was observed in an intensive care unit (ICU), further, on the post-operative care, she was administered anticoagulants (Heparin-5000U) and fibrinolytic (Tenecteplase-40mg) infusions. Dose adjustments were done by monitoring of aPTT (ranges from 35.3, 37.8, 39.6 and 46.7) and fibrinogen values (181.3 mg/dl, $212.4 \mathrm{mg} / \mathrm{dl}, 129.8 \mathrm{mg} / \mathrm{dl}, 155.8 \mathrm{mg} / \mathrm{dl}$ and $143.2 \mathrm{mg} / \mathrm{dl})$. The patient was shifted to the ward after the removal of the IVC filter; she was stable and kept for observation (aPTT 37.2 and fibrinogen on discharge $117.4 \mathrm{mg} / \mathrm{dl}$ ). The drugs were prescribed for complaints of pain and were administered with Fentanyl-25mcg patch and Tramadol-50mg. On discharge, the patient was prescribed with tablet Apixaban $10 \mathrm{mg}$ bid for a week also advised to reduce the dose to $5 \mathrm{mg}$ bid for 6 months, Cefuroxime $500 \mathrm{mg}$ bid for 5 days, Diosmin $500 \mathrm{mg}$ bid, the combination of Pregabalin and Methylcobalamin $75 \mathrm{mg}$ once daily for a month, Aspirin $75 \mathrm{mg}$ once daily to be continued. The patient was advised to take Pantoprazole $20 \mathrm{mg}$ in the morning and evening for prevention of complaints of gastric pain. Further, the patient confirmed with direct coombs test and advised to take the tablet. Hydroxy chloroquine. However, there are no signs and symptoms of SLE.

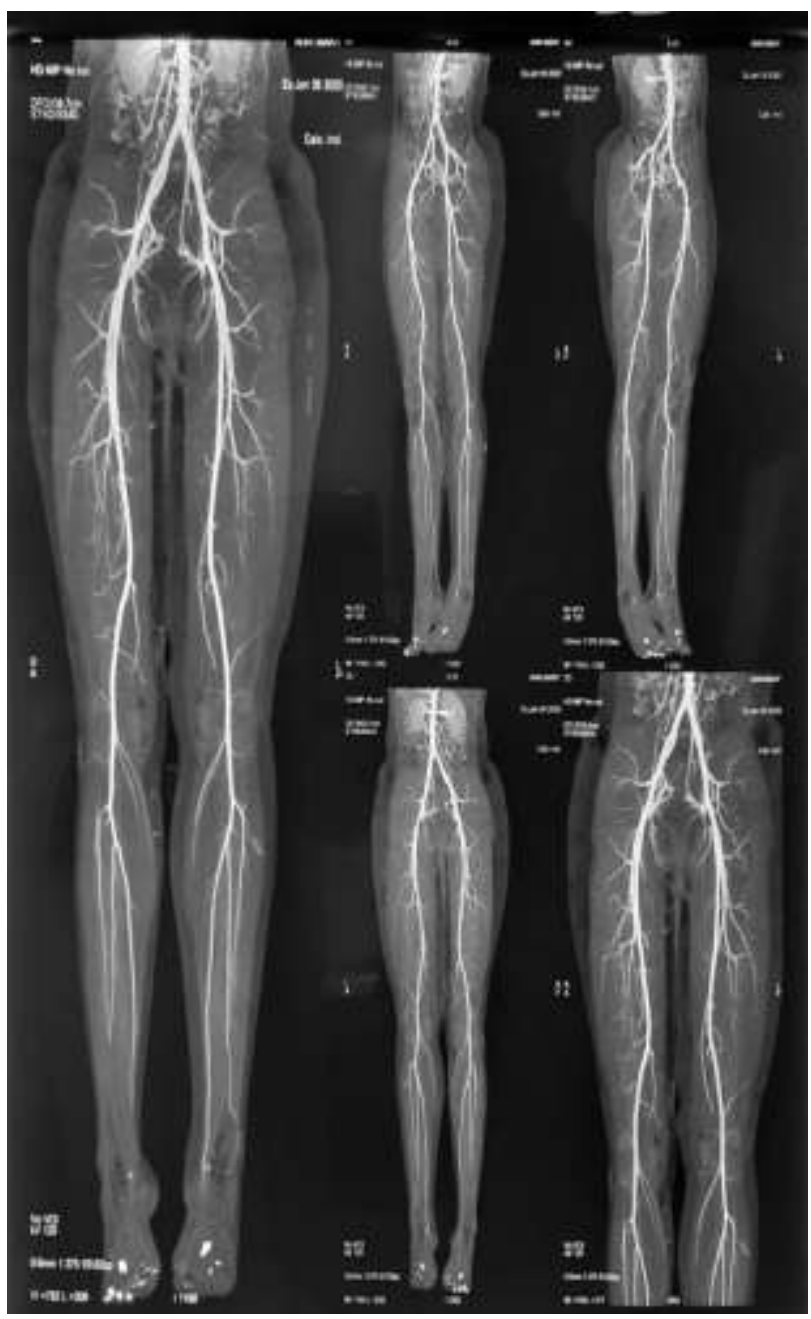

Fig-1: Doppler Venogram Ultrasound showing multiple thrombus occlusions 


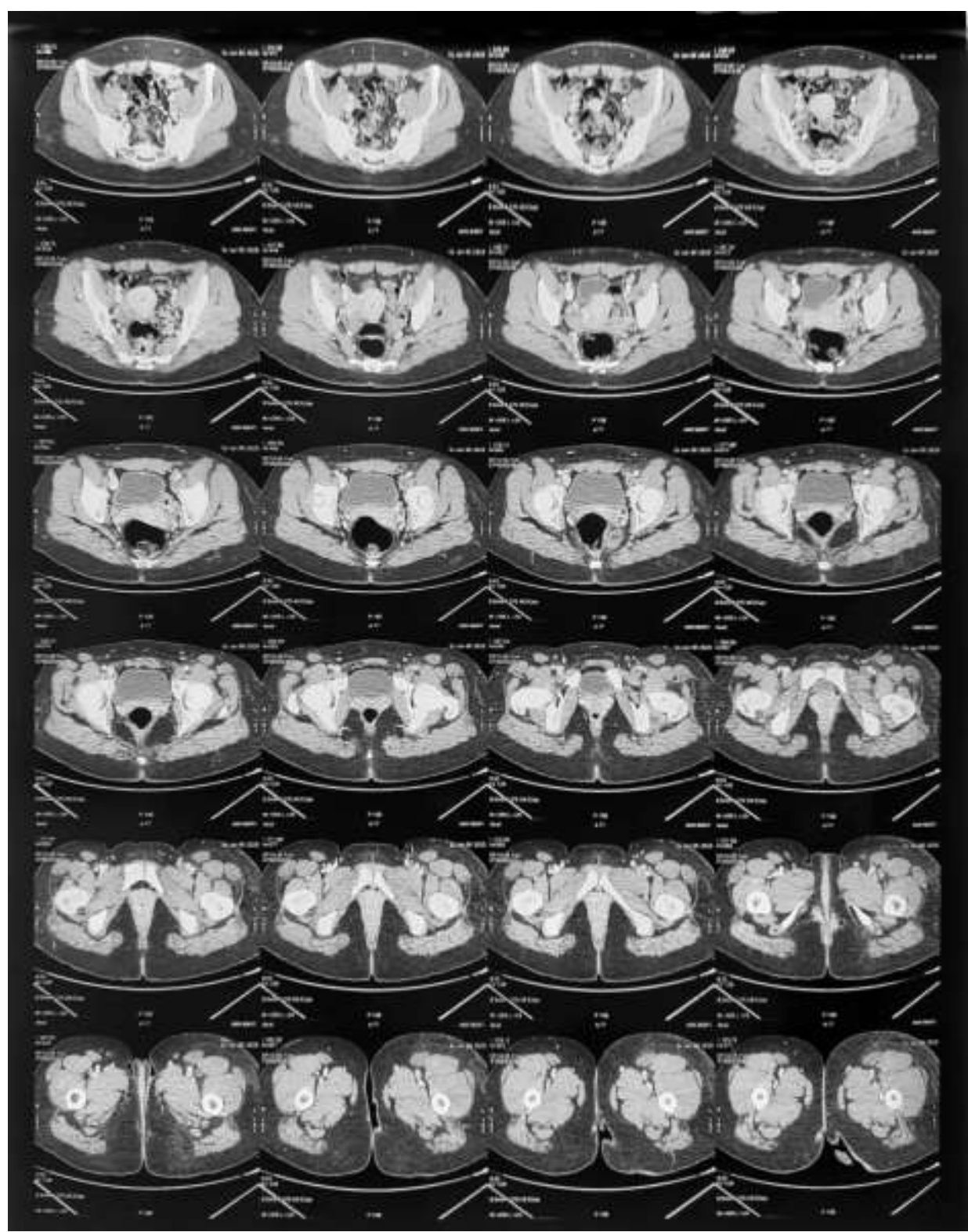

Fig-2: CT Lower Limb Venogram Indirect CTV demonstrates acute IVC thrombosis leftt external iliac vein scarring due to DVT and left common femoral vein thrombosis

\section{DISCUSSION}

Systemic lupus erythematosus widely studied with the anti-phospholipid syndrome (APS) and was comprehended as two related dependent diseases. Antiphospholipid antibody syndrome (APS) is typically characterized by the presence of either lupus anticoagulant (LAs) or anti- $\beta 2$-glycoprotein-I (anti$\beta 2$ GPIs) and cardiolipin antibodies (CAS). Recurrent venous thromboembolism (VTE) is thought to be an important risk factor among patients with APAs [10]. The underlying mechanism of thrombosis due to this APS antibodies are still not studied and explained, however, several studies have derived a proposed mechanism and explained due to activation of thrombin mediated thrombosis, APS antibodies potentiate thrombosis by pursuing $\beta 2$ GPI protein that has been accumulated to cell surfaces and thereby enhance cell activation [2,10]. Further, anti-cardiolipin antibodies bind to apolipoprotein $\mathrm{H}$ and thereby inhibit Protein $\mathrm{C}$, a required glycoprotein for coagulation cascade with regulatory function of factor V. Another hand, activation of thrombin occurs as a result of lupus anticoagulant (LAs) antibodies binding with prothrombin. In APS, protein $\mathrm{C}$ efficiency decreased due to other antibodies binding to Protein $\mathrm{S}$ (co-factor of protein $\mathrm{C})[11,12]$. In the present case the anticardiolipin (ACLA), anti-nuclear antibody test (ANA), beta-2 glycoprotein, were positive, only coombs direct test revealed positive, hence the disease confirmed primary antiphospholipid syndrome without major SLE syndrome. Other study reports expalined that around forty percent of SLE patients present with positive phospholipid antibodies (aPL). However, patients with primary APS are not reported to have other autoimmune complications of SLE syndrome. Also, these two syndromes share the same chromosomal or DNA locations for associated genetic variants, hence the 
pattern and severity, complications were similar [13]. Patients with primary APS does not develop any SLE like signs and symptoms for several years, the reason behind this mechanism still not explained, it may be due to the dominant or recessive pattern of genetic variants and gene expression variations among the individual populations [9]. Due to the complex pathophysiology and unknown mechanisms it is difficult to differentiate these two distinct disorders (SLE or APS) also these two disorders share similar sign and symptoms of systemic autoimmune complications.

\section{Conclusion}

Patients with APS suffer from life-threatening acute multiple small vessel thrombosis with high titer of the antiphospholipid antibody, potentially leading to poor prognosis, thus early diagnosis and sufficient therapeutic management required to prevent the progression of the disease.

\section{ACKNOWLEDGEMENTS}

Staff Nurses and Laboratory Technicians of Gleneagles Global Hospital are gratefully acknowledged.

\section{REFERENCES}

1. Chaturvedi S, McCrae KR. The antiphospholipid syndrome: still an enigma. Hematology Am Soc Hematol Educ Program. 2015; 2015:53-60.

2. Harper BE, Wills R, Pierangeli SS. Pathophysiological mechanisms in antiphospholipid syndrome. Int $\mathrm{J}$ Clin Rheumtol. 2011;6(2):157-71.

3. Kovács M, Hartwig M, Aleksza M, Tihanyi M, Nagy T, Vajda G. Antiphospholipid antibodies in relation to sterility/infertility. Hum Immunol. 2012; 73(7):726-31.

4. Mohammed AG, Alghamdi AA, ALjahlan MA, Al-Homood IA. Echocardiographic findings in asymptomatic systemic lupus erythematosus patients. Clin Rheumatol. 2017; 36(3):563-8.

5. Forastiero R. Multiple antiphospholipid antibodies positivity and antiphospholipid syndrome criteria re-evaluation. Lupus. 2014; 23(12):1252-4.
6. Litvinova E, Darnige L, Kirilovsky A, Burnel Y, de Luna G, Dragon-Durey M-A. Prevalence and Significance of Non-conventional Antiphospholipid Antibodies in Patients with Clinical APS Criteria. Front Immunol. 2018; 9:2971

7. Makatsariya AD, Khizroeva J, Bitsadze VO. Catastrophic antiphospholipid syndrome (Ronald Asherson syndrome) and obstetric pathology. J Perinat Med. 2018;46(4):387-400.

8. Kaul M, Erkan D, Sammaritano L, Lockshin MD. Assessment of the 2006 revised antiphospholipid syndrome classification criteria. Ann Rheum Dis. 2007; 66(7):927-30.

9. Erkan D, Yazici Y, Sobel R, Lockshin MD. Primary antiphospholipid syndrome: functional outcome after 10 years. J Rheumatol. 2000; 27(12):2817-21.

10. Tektonidou MG, Andreoli L, Limper M, Tincani A, and Ward MM. Management of thrombotic and obstetric antiphospholipid syndrome: a systematic literature review informing the EULAR recommendations for the management of antiphospholipid syndrome in adults. RMD Open. 2019;5(1):e000924.

11. Arachchillage DRJ, Efthymiou M, Mackie IJ, Lawrie AS, Machin SJ, Cohen H. Anti-protein C antibodies are associated with resistance to endogenous protein $\mathrm{C}$ activation and a severe thrombotic phenotype in antiphospholipid syndrome. J Thromb Haemost. 2014; 12(11):1801-9.

12. Ramirez GA, Mackie I, Nallamilli S, Pires T, Moll $\mathrm{R}$, Pericleous C. Anti-protein C antibodies and acquired protein $\mathrm{C}$ resistance in SLE: novel markers for thromboembolic events and disease activity? Rheumatology (Oxford). 2020; https://doi.org/10.1093/rheumatology/keaa509

13. Kamboh MI, Wang X, Kao AH, Barmada MM, Clarke A, Ramsey-Goldman R. Genome-wide association study of antiphospholipid antibodies. Autoimmune Dis. 2013; 761046. 